intravenous injection experiments were devoid of therapeutic action, at any rate, as previously citel, no slowing wals stated to have occurred on the same day after an amount of cligalen equal to 91 per cent. of the fatal close as determined in Experiment $\mathrm{V}$.

When discussing the cocflicient of distribution between the heart and the circulating fluid, deducing that digalen is safer than strophanthin, he says:

Accordingly, in trenting heart conditions of failing compensation, it is distinctly the wonker drug that is inclicated and not the stronger one, and also the more rendily soluble and diflusible one, so that accumulation may be avoided.

When this statement is made in connection with the announcement that digalen is not capable of poisoning the heart even in the concentration of one part of digalen to seventy parts of serum, it scems very favorable to digalen. It is true, indeed, as stated, that digalen is not very toxic, which is merely another way of saying that digalen has a very weak digitalis action, whether it be considered with reference to its therapentic, or toxic, action. If mere weakness is desirable, however, that can be attained with tincture of cligitalis by diluting it with from three to four times as much normal salt solution, or, better, the defatted tincture can be so diluted when a perfectly clear preparation is desired, though it is perfectly true that this may possibly have drawbacks so far as intravenous injection is concerned, and when that method of administration is desired the solution of strophanthin can be diluted to any desired degree.

While digalen is a weak preparation of digitalis, as stated, this is by no means true of the so-called amorphous digitoxin, and Moore himself states that this is capable of causing the lieart to stop beating with a conrentration of 3 parts in 5,000,000 of saline, though he ilenies such action when serum is used. This statement has been discrissed alrealy and attention is called to it again on account of an apparent discrepancy in the arguments advanced, and to slow, by Moore's own experiments, thiat the active constituent of digalen is not the weak substance that one might suppose, however weak commercial digalen in liquid form is.

The strtement just mentioned is based on Perfusion Experiment JI, in which 1 c.c. of digalen was added to a liter of saline for perfusion. It would be a somewhat plethorie rabhit of medium size, into which so much digalen could be injected at once and not exceed the concentration of 3 parts in 5,000,000 of serum, since that would require a content of 1 liter of serum, or some ten to twenty times as much as would be found in the rabbits of the sime used by Moore.

It is quite thue that the toxicity of the digitalis bodies depends to a very large extent on the concentration in which they rencli the heart, but that does not alter the fact that total quantity has something to do with the intoxication also, and when the limits of dilution are approached, it must be obvious that the abstrnction of a very small amount would reduce the total below the point where there would be any action if the amount of jerfusion fluid or serum were very small, and that the larger the volume bathing the heart the more that there would be to abstract before the concentration would fall below the point at which action would continue. But, as already pointed out, the true explanation of the difference in the action when 1 c.c. of digalen is perfused through the heart, and when the same amount is injected intravenously, is that in the first case the lieart alone shares with the perfused fluid the distribution of the poison, whereas when this is injected intravenously other organs take up a part of it from the blood.

It is quite possible that the eerum may give up dignalen less readily than does saline, but no evidence is afforded by Moore that digalen acts differently from the other digitalis bodies in this respect.

It is the mission of the critic to examine in detail any work which bears on the questions which concern hin, and it is because it seemed to me that Moore's results and conclusions would tend to give the general practitioner too high an opinion of digalen, with a correspondingly poor opinion of digitalis and its preparations that the present task was undertalien.

It is not impossible that digalen may have a place in therapentics, but, obviously, a very limited field of usefulness, in the present state of our knowledge; it is equally obvious, however, that nothing but disappointment can result from its use under a total misapprehension of its relative and actual value in the treatment of cardiac disease.

It will be evident to the most obtuse that the conclusions at which Moore arrived are quite different from my conclusions.

It is safe to say that Moore's conclusions are pleasing to the manufacturers of digalen, and when manufacturers of proprietary preparations find literature suited to their purposes of advertising they proceed, very naturally, to make such use of it as they deem best, and it would not be at all surprising if Moore's article were circulated either in the form of reprints, or by means of liberal abstracting in medical journals.

414 East Twenty-Sixth Street.

\section{TRACHOMA, ITS ETIOLOGY AND TREATMENT}

L. W. CRIGLER, M.D.

Assistant Surgeon, Manhattan Eye and Enr IJospital; Assistant Ophthalmic Surgeon, Presbyterinn IHospltal, OutPatient Department NEW YOIK

Trachoma is a disease of the conjunctiva, in which there is a characteristic connective-tissue hyperplasia. It is marked by a proliferation of lymphoid cells. The follicles formed by this proliferation tend to degenerate and to become encapsulated by the newly formed connective tissue. As a result of this inflammatory process, newly formed blood-vessels penetrate these follicles. 'Tley become distended with fluid, push their way above the surface of the conjunctiva, finally becoming degenerate, break down, and the overlying conjunctiva is replaced by scar tissue, and thus, step by step, the entire conjunctiva becomes destroyed. As a result of this chronic inflammatory process, connective-tissue changes take place in the deeper structures of the lid, normal blood-vessels become obliterated, all glandular secretion is checked and there is produced a general atrophy of the lid.

It was a little more than a hundred years ago that the significance of this disease began to be appreciated. When Napoleon invaded Egypt, in 1798, his soldiers were attacked witl a violent form of ophthalmia. When they returned to Europe, those so suffering were discharged from the army. Similar outbreaks occurred wherever these discharged soldiers went, and thus the disease became disseminated throughout the country. 'Ihis was thought at that time to have been the first 
introduction of trachoma into Furope, but subsequent investigations proved that it had existed there for centuries previously.

As to the contagionsness of trachoma, there can be no cloubt. For the past hundred years it has been a menace to the problems of military hrgiene in the European armies. Wherever large bodies of men are congregated, where intimate contact and foul air are unavoidable, rapid dissemination is certilin.

In this country, those who live in the tenement districts of the large cities are living in constant danger of infection. Let one child in a large family of children become infected, and the contagion will attack them all.

Safford, in his excellent paper on trachoma, states that on the long voyages from Italy to South America on emigrant ships, the Italian government has found it necessary to segregate in a special part of the ship those passengers who are found, after a prescribed special medical examination by government officials, to be afflicted with trachoma, even though the countries to which they are going do not as yet exclude trachomatous immigrants.

"On the stenmship Oldenburg, arriving at Baltimore in February, 1007, sixty-seven persons from the same compartment were found to be suffering from an inflammatory affection of the eyes, of the same general type, the origin of which was apparently due to the presence in their midst of four cases of trachoma in a state of acute exncerbation. Of these sixtyseven afficted passengers, forty-eight developed trachoma, subsequently, while the remainder promptly recovered, under simple remedial mensures."

The violence of the onset seems in some way related to the enviromment of the inilividual, conditions as stated above, being directly conducive to the more aggravated types. Improved methods of sanitation, and laws regulating immigrant traffic, have done much to minimize the frequency of these epidemies, and so to-day, except in the hot-beds of trachoma, acute onset is unusual.

Despite our intimate knowledge of the pathology of this disease, its etiology is still unknown. A summary of the work done during the past four years in this direction centers about the so-cilled trachoma corpuseles, or trachoma bodies. Halberstrelter and von Prowaczek, in Java, were the first to deseribe these bodies. Almost simultaneously Professor Greeff and his coworkers succeeded in finding and describing similar bodies. Fleming, from a review of the litcrature on the subject, is enabled to classify four different types, of which he considers only two as positive. These corpuscles have been found not alone in trachomatous eyes, but in eyes entirely free from any evidence whatsoever of trachoma. Stargart claims to have found them in a ease of blemnorrher neonatorum. Fleming found them associated with gonococei, repentedly, in connection with ophthalmia neonatorum. In one case, for the first few days only trachoma bodies were foumd; after the fifth day, both trachoma bodies and gonococei were present for several days, followed by a disappearance of the trachoma bodies. The gonoecesi continued to be shown for about ten weeks, when finally they disappeared and the trachoma bodies rcappeared. Thicy have been found at times in the gonorrheal urethria of both males and females.

The obseurity of their origin and the varied character of their morpliology have led some of the investigators to consider the question as to whether we are dealing with a microorganism, a parasite, or a degenerate cell. Some adhere to the latter theory, and not without some foundation; for not only have these bodies not been isolated, but efforts to obtain them in pure culture have been unsuccessful. The consensus of opinion, however, is that they have some pathologic significance in relation to trachoma. They are found in the conjunctival epithelial cells. They present the appearance of minute diplococci situated in the protoplasm of the cell. They multiply until they occupy the entire body of the cell, pushing the nucleus to one side. As they increase in number, a reactionary product or zone forms about them, which finally gives way, liberating these corpuscles with a destruction of the cell-body. Trachoma has been communicated to apes and orang-outangs by inoculation, but as yet Koch's law has not been fulfilled.

The first point that I should like to emphasize is that trachoma is essentially a chronic disease, and that; with each succeeding month of its duration, new features arise to annoy and harass the unfortunate patient. Those who are not actively engaged in the treatment of trachoma, but refer their cases to the clinics which fall heir to most of them, cannot conceive of the terrible liandicap which trachoma imposes on its victim. Years, as a rule, elapse between the time of its incipiency and the terminal stage of cicatrization, and, unless the patient is so fortunate as to have the disease arrested early by intelligent treatment, partial impairment of vision or total blindness is the result, and thus these poor unfortunate individuals become a burden to themselves and society.

While it is true that we do see cases of trachoma that run a very rapid and malignant course in the beginning. these are the exceptions that prove the rule, and it is thought by some that this violence of onset is due to a superadded infection. The typical patient presents himself at the office, or more often the clinic, stating that he was sent by the school physician or nurse to have his eres examined. The patient has noted a stinging, burning sensation in the eyes at times, and an occasional slight redness of the eye-lid, with slight secretion, but the inconvenience was not enough to prompt him to seek relief. Some of these patients have been afflicted for months before they are seen for the first time; indced. interference with vision and associated photophobia and Jacrimation are sometimes seen on a patient's first visit.

The clinical picture of this chronic type is as follows: On inspection we note a slight drooping of the upper lirss; the lids also appenr thicker than normal, and the palpebral conjunctiva of hoth lids is studded with numerous translucent lymphoid follicles, varying from the size of a pin-head to that of a small grape-shot. In the early stage, these follicles are confined to the retrotarsal fold of the upper lid, and this must be doubly everted, while the patient is told to look downward, before they can be seen.

At this point it might be well to emphasize the great similarity between trachoma and follicular conjunctivitis. They are both prone to multiply under similar circumstances of bad air and overerowding in public buildings. The follicles, both microscopically and maeroscopically, are identical. In the early stage of trachoma there is very slight, if any, thickening of the conjunctira. The arrangement of the follicles in rows are said to be characteristic of follicular conjunctivitis. In follicular conjunctivitis there is never any permanent thickening of the conjunctiva.

It is greatly to be deplored that there is no diagnostic point that will enable the general practitioner to sepurate these two diseases-to say nothing of the difficulty which the specialist encounters. We must wait until the second, or hypertrophic stage, before we can be sure of our diag- 
mosis. Conjunctivitis that does not result in a hyperplastic granular destruction of a part of the nalpebral conjunctiva cannot with certainty be called trachoma. The distinguishing difference between trachoma and follicular conjunctivitis is that the latter tends to spontaneous recovery, leaving a normal conjunctiva. Trachoma never does. I am convinced that a great many of our patients who get well under expression have cases of follicular conjunctivitis. All doubt as to the diagnosis is latid aside when the disease reaches its second stage, or that in which there is a hypertrophic thickening of the conjunctiva, associated with a beginning destruction of the bymploid follicles and a deposition of fibrous tissue. But often months are passerl in reaching this stage, when the patient's real suffering begins with associated impairment of vision. 'The palpebral conjunctiva becomes rough from the ulceration and destruction of the follieles and the tarsal cartilage becomes thick and irregular. The effect of this rough and inflamed surface coming in constant contact with the delicate corneal epithelium is erosion of the latter. Infiltration between Bowman's membrane and epithelium occurs, bloodvessels also penetrate between these two layers and thus we have a condition known as pannus. This always begins in the upper half of the cornea and is asserted by some to be a direct transmission of the disease process to the cornea. Other's contend that it is nothing more than an inflammation due to the constant friction from the upper licl. No doulst this latter condition has a great deal to do with bringing this inflammation about. It seems a reasonable conclusion, therefore, that both factors are conducive to this condition. That they are not always present in every case of pannus is also evident, for we sometimes lanve pannus formed early, before there is any roughness of the lid, and, vice versa, there are cases in which pannus does not form, despite an extreme roughness of the lid. Safford notes that pannus is not apt to form in those eyes in which the lids lie in loose contact with the cornea.

In the thind and last stage of trachoma the disease las become or is becoming arrested. The palpebral conjunctiva reaches the atrophic stage, and, in its place, has formed connective tissue. The tarsal cartilage also chares in this atrophy. As a result the lid is no longer held in its natural position, the lashes become sources of constant irritation from their inturning to the already inflamed comen, and thus the pannus that was produced by the roughener conjunctiva is prevented from clearing iip. Exudation finally finds its way beneath the basement membrane and becomes organized, and thus the vision of the individual is permanently impaired.

'The acute type of trachoma differs from that already described in its first stage only, and it will only be necessary to refer to it briefly. The onset is sudden. The patient has symptoms of violent ophthalmia with photophobia, lacrimation and a free discharge of thin scropus. On examination, the conjunctiva appears swollen and the follicles may not have appeared; they are masked by the overlying conjunctival infiltration. Ptosis may be marlied. They do not respond to treatment, and in a few weeks the acute swelling begins to subside; connective tissue forms, and the follicles stand out prominently. Pannus is apt to appear early. The liypertrophic stage supersedes the inflammatory stage in a fow weeks, and the case begins to take on the chronic nature characteristic of the disease.

As to the medical treatment of trachoma, there has been no advance during the past ten years. It must be said, however, that the remedies which are used to combat this riscase are not without effect. The great stumbling-block in the way of a successful cure is the patient himself. The pain, loss of time, and expense of carrying out the treatment cause the patients to fail to follow the physician's actvice. For the first few weeks or months they require either the daily or alternate day .visit to the office or clinic. The two main remedies depended on to combat the inflammation and to lessen hypertrophy are silver nitrate and copper sulphate; the former in cases in which there is much secretion, or in the presence of corneal ulcers, the latter, in cases in which there is marked hypertrophy. Both are extremely painful and persistently so. After a few weeks' treatment, symptoms are relieved and the patient dois not return for trentment. Presently a relapse oceurs, ulceration and destruction of conjunctiva sets in, and the patient's vision becomes impaired from corneal involvement, and the disease has progressed beyond the stage in which a cure is possible.

Txpression is indicated in those cases of trachoma presenting numerons follicles in the retrotarsal folds, as well as on the palpebral conjunctiva. This operation does not bring about a cure of trachoma, as some might think. It merely lessens congestion, emptics the contents of the follicles before the conjunctiva overlying them has been destroyed, and also makes the application of remedial measures more effective. That a great many cases of true trachoma have been arrested or cured by the combined method of expression and treatment with copper. there is no doubt, but, as said before, we are sure that a great many instances reported of successful cures are not cases of tracloma. I am firmly convinced that no cases that respond to expression, in a few weeks after treatment, should be classified as trachoma, although at the time they present precisely the same picture. This differentiation is emphasized for the reason that the physician, noting the successful results following expression, with very little attention to the after-treatment, is almost certain to fail to emphasize to the patient the importance of the after-treatment, and it is for this reason that relapses occur so often. The disense is allowed to progress into the hypertrophic stage, with beginning cicatrization, when successful cure by any and all methods becomes impossible, and a resort to surgical monsures is the only means of relief at hand. 'This is an ncknowledgment in itself of our inability to combat the discase successfully.

The surgical trentment of trachoma, as outlined by Professor Hiesrath, of Königsloerg. and later modified by lis pupils, Vossius and Kuhnt, has not received the recognition that it so justly deserves. Their results for the past ten years have been so uniformly successful, and their theories were based on such common-sense principles, that it is difficult to understand why this operative procedure has not been adopted wherever trachoma is found. These men recognized, in advanced cases of trachoma, the utter failure to arrest the disease by medical or mechanical (expression) means. They olsserved, in cases of old trachoma, in which a cure had been brought about by Nature, a complete obliteration of the retrotnrsal folds, a shrunken and distorted cartilage, with its subsequent cvil effects, a pannus that was dense and permanent, a complete destruction of all follicles and a dry and shrunken conjunctiva. With this picture, then, before them, their argument must have been: Since this disease process will not subside until 
the tissues involved are destroyed, why not remove them at once, and thus save the patient the time and suffering which Nature takes years to accomplish? Their reasoning was correct, as demonstrated by their results.

To Dr. H. W. Wootton credit is due for having brought this subject before the inedical profession of this country. Although he was not the first to perform this operation here, he has done more than anyone else toward establishing it as a recognized surgical procedure.

The two operations indicated in advanced cases of trachoma are, first, a removal of the tarsal cartilage of the upper lid, together with its overlying conjunctiva

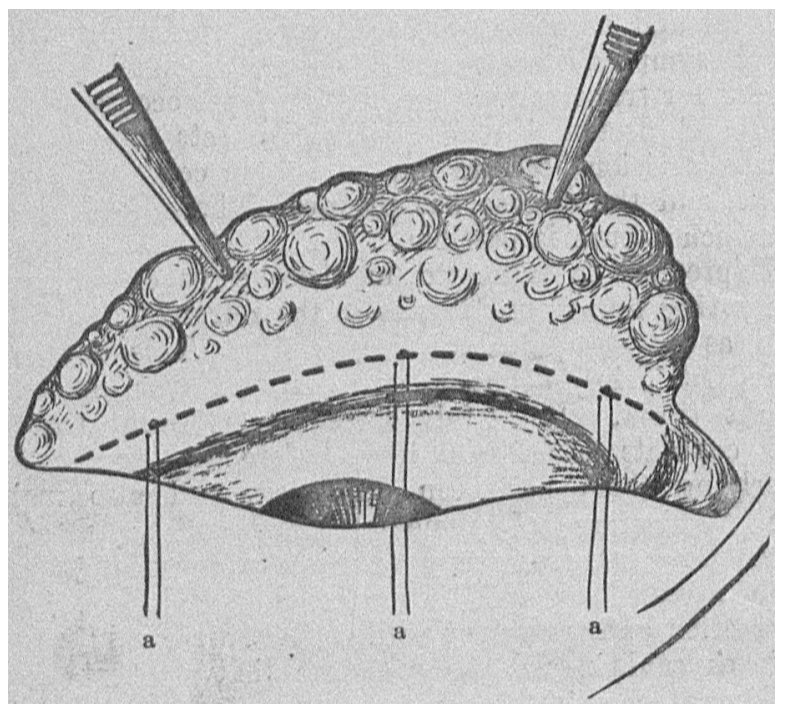

Fig. 1.-I Doubly everted upher. lid; a, sutures; line of dashes, line of upper Incision.

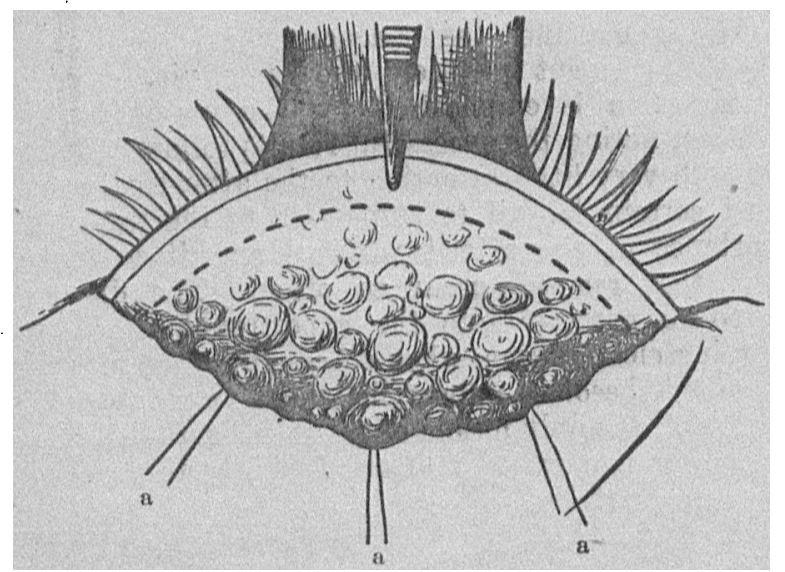

IIg. 2.-Upper IId everted; a, sutures; line of dashes, line of Jower incision.

and retrotarsal fold; second, a removal of the tarsal cartilage of the upper lid, alone. 'The former procedure is indicated in the beginning cicatricial stage, where roughened and uleerated follicles still remain; the latter, where the follicles have been replaced by connective tissue, and the cartilage, while still hypertrophied, is undergoing retrograde changes which result in a distortion of the lid. In some cases the lids become everted. Entropion, lowever, is most common. Pannus that forms in the lyppertrophic stage is prolonged into the cicatricial by distortions of the lid-margins, or an irregularity in the cartilage itself.

The operation of removing the cartilage and conjunctiva is termed combined excision, and is briefly described as follows: The upper lid is doubly everted by means of fixation forceps and horn. A horizontal incision is made through conjunctiva alone at the junction of ocular and palpebral conjunctiva (Fig. 1). The cut margin of the bulbar conjunctiva is slightly undermined, and three sutures are passed equidistant. The sutures are sufficiently long to admit of a needle at each end. The lid is now singly everted, and another incision $2.5 \mathrm{~mm}$. from, and parallel to, the lid-margin is made through conjunctiva and cartilage (Fig. 2). The ends of this incision are made to unite with the posterior one, and the conjunctiva and cartilage are gently dissected away, care being taken not to remove any of the tissues beneath the cartilage, and to leave a very thin strip of cartilage above, if possible, to prevent injury to the attachment of the levitor muscle. Next, the three sutures placed in the bulbar conjunctiva are drawn forward, each being armed with two needles, and are passed from within out, one end passing through the cut edge of the cartilage, the other just posterior. This causes coaptation of the bulbar conjunctiva with the $2.5 \mathrm{~mm}$. strip of conjunctiva remaining; the fornix is obliterated. The sutures are tied over a wick of gauze, and the operation is completer. The diseased tissue has practically been removed, and

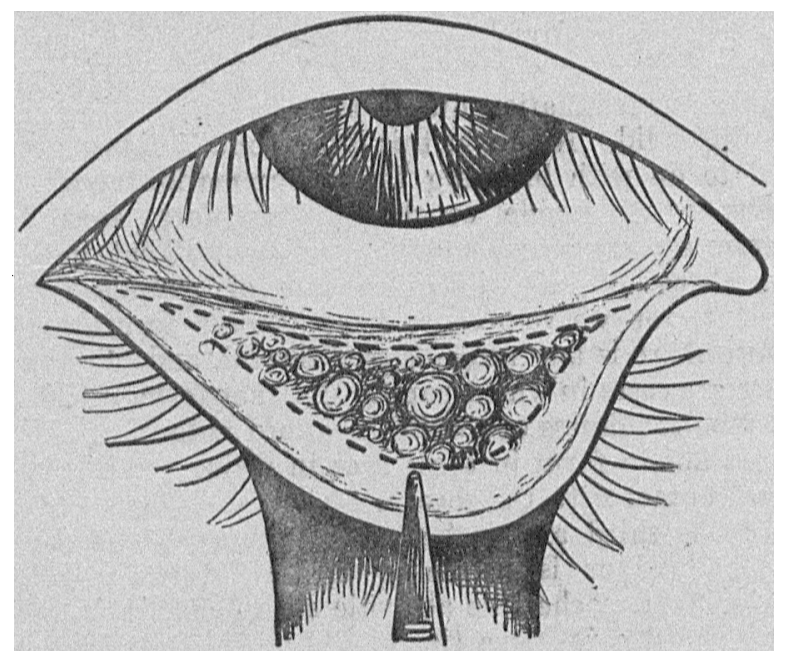

Fig. 3.-Lower lid everted; lines of dashes, lines of Incision.

thus we accomplish in half an hour what Nature takes year's to do.

The results in a hundred or more of these patients, operated on by Dr. Wootton, myself and various other members of the staff of the Manlattan Eve and Ear Hospital during the past two years, demonstrate beyond doubt that this is the most successful means known of combating this condition. Careful statistics of these cases were not made, but the percentage of cure has been at least 75 per cent. By this I mean a complete arrest of all inflammatory action, a rapid clearing up of pannus, except in those cases in which ulceration had taken place, with resulting permanent opacities.

A resort to tarsal resection alone is less frequent, and the results, when the operation has not been done until late, less gratifying. The procedure is simple. The lid is everted, an incision through conjunctiva and cartilage is made $2.5 \mathrm{~mm}$. from, and parallel to, the lid-margin, the cartilage is carefully dissected both anteriorly and posteriorly, removed, and the conjunctiva sutured in its original position, in a manner similar to that described in the preceding operation. Neither of these operations restricts the motility of the eye-ball, or interferes with 
the movement of the lids. They relieve ptosis and entropion rather than produce them, and, aside from a slight furrow or fold in the skin which is sometimes more than normal, produce no outward deformity. In the majority of cases pannus begins to clear up in a few days and the progress is rapid. Granulations sometimes spring up in the line of incision, especially if coaptation is imperfect, and may retard recovery. These may be removed with a strong solution of silver nitrate, or even the stick, provided only granulations are toucherl. Oecasionally a dislocaterl eyclash becomes a source of irritation to the cornea. Such eyelashes should be removed with electric neetle, or else regularly with cilia forceps.

Trachoma involving the lower lid does not lead to the bad results that are produced by the upper; where there is pronounced involvement, however, it acts as a souree of constant irritation and retards recovery. Removal of the palpebral conjunctiva alone is here indicated, since the disease does not seem to involve deeper structures; besides a removal of the tarsal cartilage would result in immediate entropion. 'J'he procedure is simple, the two lines of incision being similar to the ones in the upper lid (Fig. 3), care being taken not to eneroach on the bulbar conjunctiva behind, or througl the tarsal cartilage in front. The conjunctiva is dissected away, and the raw surface is left to granulate and cicatrize over. The cartilage being left in place, no deformity follows. Should granulations become too exuberant, they should he removed by scissors or cautery. In a few weeks the surface has become smootl.

4) East Forty-First Street.

\section{A NEW PNEUMO-FLECTRIC PROCTOSCOPE $\triangle N I)$ SIGMOIDOSCOPE}

\section{FRANK C. YEOMANS, M.D.} NEIV YORJ

Rectoscopy and sigmoidoscopy are now firmly established as the scientific method of examining the terminal segment of the large intestine. In patients having symptoms referable to the large bowel, it is no longer a question of the value of rectoscopy and simmoidoscopy, but of the simplest and most efficient instrument for this purpose. Hitherto the practical methods of direct electric illumination of the proctoseope bave been by carrying small incandescent bulbs near the distal end of the tulbe on insulated caryiers.

Previous attempts at direct illumination of proctoseopes by a light within and at the proximal end of the tulue have heen few and the resulting instruments complicated and unpractical. Recently, however, Dr. James R. Hayden ingeniously conceived a new principle of thus ligliting a tube and his idea has been eleverly executed in the Hayden urethroscope. By his courtesy I have adapted the same system of lighting to the proctoscope, simplifying the tube, however, to meet the requirements of proctoscopy and sigmoidoscopy.

The new proctoscope consists of:

A. A tube 10 inches long and of seven-eighths inch diameter, graduated in inches, its distal end slightly ol)lique and the proximal end fitted with a large flange with milled edge and a small segment cut from one side to prevent rolling. An auxiliary tube perforates the flange and joins the main tube at an angle.
B. Illumination is direct and is obtained from a small but powerful electric bulb which is covered with a capsule bearing a plano-convex lens so set that the collected rinys are refracted at a compensating angle to the light-carrier. The light is mounted on a carrier which fits accurately by a conical fitting into the anxiliary tube while only the lens projects into the main tubre, focusing all the rays at its distal end and in no appreciable degree interfering with the vision of the observer or the introduction of instruments for examination, local applications or operation.

C. A metallic plug closes hermetically the proximal end of the examining-tube by a conical fitting and contains a glass window wlich magnifies the illuminater field at the distal end of the tulse. This plug is perforated at the side for a small off'set with a nipple for the attachment of a hand bull to inflate the bowel to any desired extent. The conical fitting of window and light-carrier prevents escape of air when pneumatic pressure is applied and there is great facility in removing or inserting light or window.

D. The obturator has an olivary tip which facilitates the introluction of the tube, and a broad handle so that it rloes not roll on a flat surface.

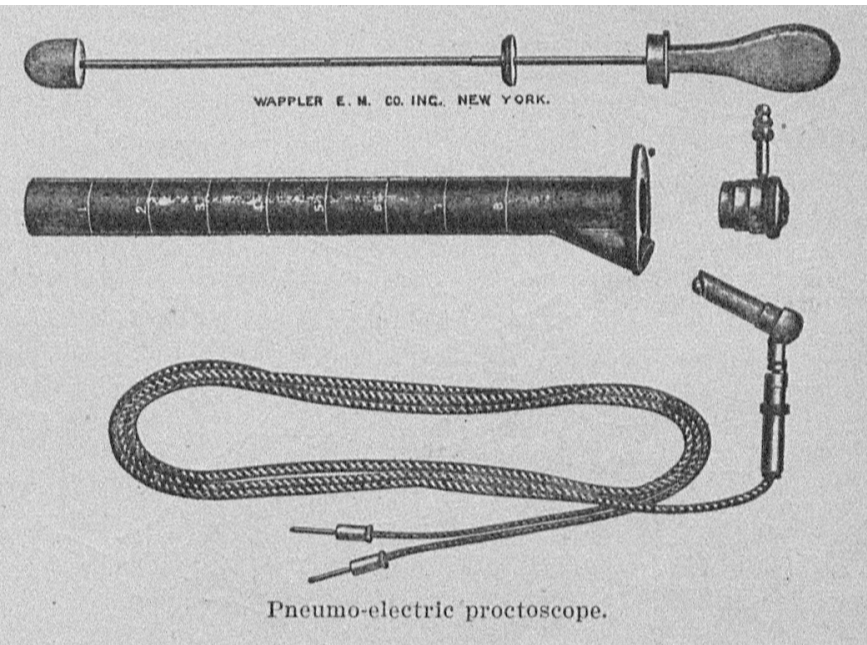

The tubes are of three sizes, (1) proctoscope, 10 inches long and of $7 / 8$ inch diameter; (2) sigmoidoscope, 14 inches long and of $3 / 4$ inch diameter; (3) infant's proctoscope, 9 inches long and of $1 / 2$ inch diameter, for examining children and strictures.

'The same light-carrier fits all these tubes, but a smaller window is used for the infant's proctoscope. For the general practitioner the 10-inch proctoscope will be found most useful and will fill all requirements in the great majority of cases. The source of light may be either a six-cell dry battery or the street current with the usual electric controller interposed.

The features of this new instrument are:

1. Simplicity.

2. The fact that the instrument is sterilizable by boiling.

3. Direct illumination by a substantial bulb which will not bur'n out easily.

4. The same light-carrier for all tubes.

5. Thorough practicability for the examination, dingnosis or treatment of all abnormalities occuring within the rectum or sigmoid flexure below its apex.

40 West Forty-Iighth Street. 